\title{
AVALIAÇÃo EDUCACIONAL
}




\title{
AVALIAÇÃO NO ENSINO DE HISTÓRIA: SIGNIFICADOS E POSSIBILIDADES
}

Décio Luciano Squarcieri de Oliveira

\begin{abstract}
Resumo
Este ensaio constitui-se como parte da pesquisa realizada no Mestrado em Educação da UFSM, sendo aqui problematizados alguns dos muitos significados da avaliação da aprendizagem e trazendo-se, como proposta, atividades que intensifiquem os diálogos em detrimento da exclusividade do conteúdo. A metodologia empregada é o estudo de caso (LÜDKE; ANDRÉ, 1986), uma vez que se pesquisa o tema da avaliação em sua singularidade, mas compreendendo-a dentro da multiplicidade da Educação e do contexto em que se manifesta. Sua abordagem qualitativa dedica-se a conhecer o tema como pertencente a um processo e interpreta a avaliação por meio do significado que os próprios sujeitos "dão às coisas e à sua vida". Uso como fonte de dados um questionário sobre a representação do professor (a) de História, encaminhado aos acadêmicos do curso de Pedagogia do quinto semestre, no ano letivo de 2009. As referências seguem-se por Aróstegui (2006); Bezerra (In: KARNAL, 2005); Vasconcellos (2001); Hoffmann (2003); Jovchelovitch (1998) e Henriques (In: AZEVEDO, 2006).
\end{abstract}

Palavras-Chave: Avaliação. Ensino de História. Formação Docente

\section{EVALUATION IN THE TEACHING OF HISTORY: MEANINGS AND MEANS}

\begin{abstract}
This paper is constituted like part of the inquiry carried out in the Master's degree in Education of the UFSM, when there are here problem some of many meanings of the evaluation of the apprenticeship and present like proposal, activities that intensify the dialogs to the detriment of the exclusiveness of the content. The employed methodology is the case study (LÜDKE; ANDRÉ, 1986), as soon as it investigates the subject of the evaluation in his peculiarity, understands them to me same inside the multiplicity of the Education and of the context in which it is shown. His qualitative approach is dedicated to know the subject as pertaining to a process and interprets the evaluation through the meaning that the subjects themselves "give to the things and to his life". I use like fountain of data a questionnaire on the representation of the teacher (a) of History, directed for the academics of the course of Pedagogy of a fifth one semestre/2009. The references follow for Aróstegui (2006); Bezerra (In: KARNAL, 2005); Vasconcellos (2001); Hoffmann (2003); Jovchelovitch (1998) and Henriques (In: AZEVEDO, 2006).
\end{abstract}

Keywords: Evaluation. Teaching History. Formation Teacher 


\section{L. Squarcieri de Oliveira}

\section{Introdução}

Para compor este artigo, em suas linhas iniciais, gosto de destacar que o estudo do tema da avaliação, mais especificamente da avaliação da aprendizagem e dela no ensino de História, está longe de oferecer respostas às muitas indagações que são realizadas.

Estudar avaliação ao meu modo de ver, por si só, já é um avanço, quando, em uma rápida pesquisa nos acervos das bibliotecas, encontramos poucas obras, dissertações ou artigos em que o autor tenha uma formação em licenciatura específica, como no meu caso, em História, e que traga a pesquisa com avaliação para suas análises.

Quando me proponho escrever sobre a avaliação da aprendizagem no ensino de História, e mesmo antes disso, ao justificar meu interesse por este tema de constituição elementar da docência de História, o faço com base em algumas recordações que trago comigo do meu tempo de aluno, em meus anos escolares na educação básica, e das formas como fui 'avaliado' nesta disciplina. Destaco a palavra 'avaliado', porque sempre considerei tratar-se de um momento à parte de todo o meu 'processo' de aprendizagem, mesmo que esta aprendizagem nem sempre tenha sido encarada como processo.

'Avaliado', neste tempo de minhas lembranças, ocupava um lugar desconectado das minhas aulas, das explicações dos professores, dos trabalhos em comunhão com meus colegas. Era um momento reservado e destinado a ser realizado em um dia marcado, com tempo determinado e conteúdos bem delimitados, que careciam de alguns dias ou horas de estudo antes da realização da 'prova' ou 'teste'. Não o recordo como sendo um momento agradável. Nem mesmo quando eu 'passava' na prova, obtendo a aprovação, hoje interrogada por mim se não era apenas uma 'passagem' mesmo.

Caso a 'nota' estivesse em 'vermelho', indicava que meu desempenho escolar estava baixo, o que, em alguns casos, ia se acumulando em provas e o resultado sendo sempre repetido. Se a avaliação não me provocasse nenhum sentimento, como de agonia e até medo, não teria razão eu de esconder as 'provas' do crime que eu cometia. Os esconderijos eram muitos, dada tanto a criatividade, como o temor por mostrar aquelas avaliações em minha casa, ao meu pai, que considerava a nota 'baixa' como um indicativo de falta de estudo, de empenho e de dedicação em minha única tarefa juvenil: estudar. 
Para o imaginário de seu tempo, eu deveria 'aprender' tudo o que o Professor 'ensinava', sendo a disciplina de História uma matéria 'fácil', já que era preciso apenas 'decorar' as datas e os nomes que estavam escritos nos livros didáticos, que custavam muito caros, ou dos polígrafos empregados nas escolas públicas. Para ele, não tendo a necessidade de fazer cálculos, nem escrever textos extensos, não havia justificativas de minha parte por não ser aprovado.

Aqui, já vamos encontrando alguns dos elementos que permeiam o imaginário da avaliação da aprendizagem e que ainda hoje fazem parte das nossas escolas e professores (as) atuantes na disciplina de História, como a facilidade dos conteúdos da disciplina e a legitimação de avaliar os alunos mediante uso de provas escritas a partir das técnicas de memorização.

Quanto mais eu reprovava em uma disciplina, menos gostava de seus conteúdos e menos ainda gostava da figura que ministrava aquele conteúdo. As imagens que meus professores adquiriram, em especial da disciplina de História, eram de pessoas autoritárias ao extremo, sempre apressadas em suas falas, com palavras de difícil compreensão e que exigiam textos copiados, “cobrando" questões destes mesmos textos que deveriam ser preenchidas com respostas 'exatas', isto é, as respostas correspondiam àquelas copiadas no caderno ou de acordo com as suas exposições orais em suas aulas.

As experiências por mim vivenciadas não mudaram muito no curso de graduação em História, mas serviram para contrabalançar tais situações com as tentativas de outros professores em proporem formas diferentes de avaliação. Mesmo sendo um curso de formação docente, não havia prioridade no estudo dos elementos constituintes da docência, sendo que muitas das formas empreendidas continuavam guardando semelhanças à educação básica.

No momento de meu estágio, ao final da minha graduação, desejava conhecer mais sobre avaliação da aprendizagem, em especial quando me questionava se os instrumentos com que os meus professores na Universidade me avaliavam não eram definidos com base na forma e, principalmente, no significado adquirido por eles, na condição de alunos.

Em qual tempo e lugar a avaliação aparecia no planejamento destes professores e realmente essa questão era preocupação deles como para mim o era/é? As semelhanças entre os objetos de avaliação e os níveis de ensino eram tão próximos, que tal questão me instigou, a ponto de elaborar um questionário para meus alunos no ensino fundamental, nível em que 


\section{L. Squarcieri de Oliveira}

estagiei, onde pretendia verificar como eles percebiam a avaliação e os professores de História. Na época, tal atividade me aproximou dos colegas docentes que atuava $\mathrm{m}$ na escola, os quais me relatavam que, em determinadas ocasiões, pensavam a avaliação com base em suas memórias educativas como alunos. Outros, por sua vez, destacavam que somente a 'prática' me responderia essa inquietude.

Hoje, em meu projeto, eu questiono: qual (ais) é (são) a (s) imagem (s) da avaliação da aprendizagem e da (o) disciplina/professor (a) de História que se adquire/forma nos trajetos de formação e quais são os lugares de formação que se adquire/forma (m) o (s) seu (s) significado (s)?

Neste artigo em particular, a questão é direcionada por: que imagem (s) representa o Professor (a) de História para os acadêmicos do Curso de Pedagogia Licenciatura Plena, que, em 2009, encontravam-se em seu quinto semestre? E frente a essas imagens, como podemos discorrer sobre os elementos constituintes do processo educacional, entre eles, a avaliação.

\section{Avaliação e alguns dos seus muito significados}

Quando iniciamos pesquisas na área da Educação, é corrente encontrarmos, na bibliografia consultada, a preocupação do estudo, que se propõe, fornecer uma utilidade social para justificar-se. Além disso, somos pautados pela indagação: onde em certo momento se espera que o estudo seja capaz de oferecer uma 'funcionalidade prática'. Em se tratando de pesquisa com abordagem qualitativa, essa questão não ocupa centralidade, uma vez que:

\footnotetext{
A pesquisa qualitativa tem o ambiente natural como sua fonte direta de dados e o pesquisador como seu principal instrumento. [...] os problemas são estudados no ambiente em que eles ocorrem naturalmente, sem qualquer manipulação intencional do pesquisador. [...] A preocupação com o processo é muito maior do que com o produto. O interesse do pesquisador ao estudar um determinado problema é verificar como ele se manifesta nas atividades, nos procedimentos e nas interações cotidianas. [...] O "significado" que as pessoas dão às coisas e à sua vida são focos de atenção especial pelo pesquisador. Nestes estudos há sempre uma tentativa de capturar a "perspectiva dos participantes". (LÜDKE; ANDRÉ, 1986, p.11-12)
}

Para o pesquisador qualitativo, compreendo que sua atenção é direcionada para um foco específico, de seu interesse, logo, carregado com 
suas visões pessoais para efeito desta seleção, o qual empreenderá esforços para desvendar seus significados, a partir de um olhar sensível, superando a imagem que seu objeto/sujeito lhe fornecer, analisando com cuidado a formação histórico-social deste mesmo foco.

Como almejo realizar esta abordagem, também se faz necessário que o conhecimento produzido, por meio de questões, seja mutante em seu movimento constante de descobertas, construtivo deste tempo e espaço, com a qualidade de carregar a capacidade de mudança de significados, na medida em que novas fontes surgirem e novos olhares forem direcionados para o estudo. Assim, percebo a questão da utilidade e da funcionalidade em detrimento da oferta de elementos capazes de estimular a reflexão.

A par destas definições, sinto necessidade de trilhar estes caminhos em minha pesquisa, em que, ao escolher e ser escolhido por estes dois campos do saber - Educação e História -, encontro coerência entre os pressupostos anteriormente referidos e as minhas leituras sobre o viver e o vivido.

Por parte de minha formação inicial, a licenciatura em História - o campo de conhecimento histórico, que tem se mostrado preocupado em interpretar nossas ações onde elas acontecem, tomando como orientação teórica a 'voz' e a 'vida' de quem constrói a História no seu dia a dia, com posições "diferentes e às vezes conflitantes".

Pela Educação, lhe confiro a condição de realidade em que se almeja ver essa utilidade da disciplina de História, agregando valores adquiridos/ formados em um tempo pretérito, mas com reflexos iluminando nosso presente.

Ao trabalhar a disciplina de História no curso de Pedagogia, Licenciatura Plena, da Universidade Federal de Santa Maria (UFSM), como professor auxiliar, junto ao Departamento de Metodologia do Ensino, a cadeira ministrada tinha como objetivo geral possibilitar ao futuro professor (a) de pedagogia, ensinar a disciplina de História em suas diferentes formas e recursos, nos anos iniciais do ensino fundamental, bem como usá-la nas diferentes instâncias educacionais e sociais, os conhecimentos históricos e suas possíveis interpretações.

Atuando como professor de metodologia de História, algumas diferenciações foram necessárias abordar para os acadêmicos, a fim de apresentar suas peculiaridades, como também por acreditar que, tendo o conhecimento dos objetos/sujeitos desta área de estudo: tempo - fato - sujeitos, o futuro professor (a) agrega elementos fundamentais à elaboração de 


\section{L. Squarcieri de Oliveira}

suas significações particulares, contrariando as visões ditas "universais", que negam a ideia da disciplina de História ser uma construção constante, entendida como pertencente a um 'processo' capaz de alterar significados com base em fontes documentais variadas e teorias explicativas de raízes históricas distintas.

Para esta compreensão, faço uso dos estudos de Bezerra, que define, com clareza, a História compreendida como sinônimo de processo:

Na verdade, o passado humano não é uma agregação
de ações separadas, mas um conjunto de comporta-
mentos intimamente interligados, que têm uma ra-
zão de ser, ainda que na maioria das vezes imperceptí-
vel para nossos olhos. O processo histórico constituí-se
dessas práticas, ordenadas e estruturadas de manei-
ras racionais. São os problemas colocados constante-
mente na indeterminação do social que fazem com que
os homens se definam pelos caminhos possíveis e dese-
nhem os acontecimentos que passam a ser registrados.
Os registros ou as evidencias da luta dos agentes histó-
ricos são o ponto de partida para entendermos o pro-
cesso histórico. (BEZERRA, In: KARNAL, 2005, pp. 43.)

Dessas peculiaridades, destaco a referente ao 'tempo', pelo fato do conhecimento histórico ater-se aos eventos ou às manifestações de um sujeito ou grupo deles, sendo 'determinado' e 'limitado' como recurso didático, ao chamado 'tempo vivido'. Por sua própria constituição, este campo do saber apresenta uma impossibilidade no sentido de provocar 'mudança', se essa for entendida como 'alteração do objeto/sujeito pesquisado', ao invés da 'mudança de significação deste objeto/sujeito', visto que suas interpretações referem-se a eventos já ocorridos, a análises das sociedades e as suas ações em um tempo passado, portanto, não cabível de alterações no fato realizado.

Para efeito deste argumento, me respaldo nos estudos desenvolvidos por Aróstegui (2006), que se referenda a Koselleck:

[...] o historiador situa-șe diante do 'futuro do passado'. Toda a construção sobre o histórico trabalha com uma manipulação do tempo, uma vez que escrevemos a partir do presente sobre o passado e a concepção do futuro intervém igualmente nela. O historiador enfrenta o 'futuro do passado' de uma forma precisa: para ele, aquilo de que trata é seu passado: o tema como tal é, em sua ontologia, um presente: o historiador faz a análise de tal presente-passado à luz do que sucedeu 'depois' do que descreve como presente. Está, pois, trabalhando com um futuro passado, com um futuro do

234 REgAE, Santa Maria, v. 1, n. 2 jul./dez. 2009 
A discussão neste nível é importante como possibilidade formativa do docente de História. Pensar como se constrói o significado dos conceitos da disciplina que trabalho é visualizar a imagem e a utilidade que os alunos fazem dela. Utilidade é aqui colocada não de forma simplista, como se descartável quando não percebido o seu uso, mas capaz de instigar a curiosidade de um conteúdo que adquire significado se compreendido por processo, ultrapassando a visão linear da História. Significado também que sofre alteração quando se organiza o plano didático, uma vez que, para realizar o planejamento nesta disciplina, é preciso ter claro o significado dos seus elementos constituintes e da concepção histórico-filósofica que eles partem.

Pensando nestas características, elaborei um questionário que tinha como intenção ser distribuído no início do semestre, na primeira aula, em que os acadêmicos (a) responderiam algumas questões, a fim de que eu pudesse conhecer um pouco dos novos alunos, suas intenções na disciplina, suas constituições familiares, as participações em projeto como ainda quais as imagens que, para eles, representavam os professores (a) de História, com base em suas experiências discentes nos anos escolares, qual a imagem que consideravam ser a representação de (a) "professor (a)", e, por fim, solicitei-lhes que destacassem cinco características que demonstrassem o (a) "professor (a)".

Minha elaboração tinha por finalidade perceber qual era essa 'representação', que segundo Jovchelovitch (In: ARRUDA, 1998, p.80): "Expressam os processos através dos quais, uma comunidade produz o sistema de saberes que lhe confere uma identidade social, uma forma de enfrentar o cotidiano e uma forma de se relacionar com os objetos que o rodeiam.".

No final do semestre, trazia os mesmos questionários, por eles preenchidos, e organizávamos uma roda de discussão destas imagens e das possíveis alterações com as intenções e realizações após o encerramento da disciplina. Portanto, a avaliação final deste questionário se processava ao término da disciplina, quando o aluno, de posse dos questionários, poderia revisitá-los e traçar considerações que viabilizassem o estabelecimento de semelhanças ou diferenças.

Dentre as três questões finais, as duas últimas foram por mim elaboradas pensando em serem muito próximas, senão iguais, uma vez que pedem 'a (s) imagem (s)' que representa (m) 'o (a) professor (a)', e, na questão 


\section{L. Squarcieri de Oliveira}

seguinte, peço que destaquem 'cinco características' que 'demonstram o que é um professor (a)'. Os acadêmicos identificaram as imagens representativas do (a) professor (a) a partir de suas experiências em sala de aula, de seus anos escolares na educação básica e com algumas referências no transcorrer que estavam tendo na graduação. Ao selecionarem as 'cinco características' capazes de demonstrarem 'o que é um professor (a)', suas respostas foram destacadamente diferentes das figuras anteriores, elaboradas no início do semestre, tendo, agora, como referência, uma descrição a partir de seus desejos e anseios com a profissão docente. Desejos de terem professores com aquelas características, assim como desejos, anseios e metas para suas próprias atuações futuras na profissão docente.

Aqui encontramos alguns dos elementos presentes no imaginário educacional. A própria organização do questionário foi percebida pelos acadêmicos como sendo necessário preencher pergunta após pergunta, ressaltando-se que poucos se deram por conta que as duas últimas questões eram semelhantes.

Ao alcançar o questionário, orientei os alunos a perguntarem caso tivessem dúvidas quanto ao teor das questões. Meu pedido era para que eles expressassem suas inquietações para os demais colegas, para haver trocas de opiniões - 'experiências' de suas vidas escolares, para irem se formando professores com base nas suas 'próprias histórias de vida'.

[...] para que uma experiência seja considerada formadora, é necessário falarmos sob o ângulo da aprendizagem; em outras palavras, essa experiência simboliza atitudes, comportamentos, pensamentos, saberfazer, sentimentos que caracterizam uma subjetividade de identidades. Falar das próprias experiências formadoras é, pois, de certa maneira, contar a si mesmo a própria história, as suas qualidades pessoais e socioculturais, o valor que se atribui ao que é 'vivido'. (JOSSO, 2004, p. 47-48)

Ao contrário disso, responderam como se estivessem com tempo demarcado, conteúdos delimitados e ainda com receio se o que escreviam estava certo ou errado! Responderam como uma prova!

O imaginário da avaliação saltou aos meus olhos. As experiências escolares construíram significações capazes de separarem em momentos o que nos esforçamos para ser um 'processo': primeiro, o da aprendizagem, da aquisição de saberes; depois, pelos dias de prova, de exame, que carecem de respostas corretas, sem trocas de diálogos, sobre o risco de serem 
reprovados.

Meu problema de pesquisa se mostra atuante, questionando a (s) imagem (s) da avaliação da aprendizagem e da (o) disciplina/professor (a) que se adquire/forma nestes trajetos de formação e qual o lugar de formação em que se dá a construção dos significados? Aqui, neste artigo, imagens representativas do (a) professor (a) de História, onde nesta singularidade percebemos a multiplicidade dos elementos da Educação e da História, presentes em constantes transformações. Conforme argumenta Henriques:

Cada vez mais, é impossível pensar na existência de relações sociais ou de relações como as que envolvem a formação de conhecimento dos professores em organizações ou estabelecimentos sem levar em conta sua dimensão simbólica, considerando apenas seus aspectos físicos e materiais, sem que as pessoas se vejam nessa relação, o que inclui a imagem que possuem de si próprio e do outro. (In: AZEVEDO, 2006.)

Outra questão que cabe elucidar: se estas experiências escolares constroem significados do que é um Professor (a), neste caso específico, da disciplina de História e ainda de elementos constituintes da Educação como a avaliação da aprendizagem, quais são os instrumentos de avaliação e com quais objetivos estão sendo pensados?

O imaginário da avaliação permeia os nossos sentidos, como destaca Vasconcellos (1992, p. 31):

[...] a avaliação escolar não é só avaliação! De instrumento de análise do processo educacional, a avaliação tornou-se instrumento de dominação, de controle, de seleção social, de discriminação, de repressão, adquirindo até um caráter passional de vingança, de 'acerto de contas'

Ao ler uma obra de HOFFMANN (2003, p. 19), encontrei relatos sobre seus grupos de estudos, em uma das suas incursões, os docentes participantes foram provocados a pensar sobre a avaliação da aprendizagem: "Quando representam a avaliação através de imagens, surgem carrascos, labirintos, relâmpagos e trovoadas.", apontamentos feitos pelo autor e que são fruto dos temores que se tem ao ser avaliado, sentimentos adquiridos ao logo do trajeto de formação, o que merece uma questão: esses docentes avaliam seus alunos com os instrumentos que lhes causam a angústia anunciada?

No presente texto, não tenho a pretensão de trabalhar com quanti- 


\section{L. Squarcieri de Oliveira}

dades, por isso considero que cada sujeito respondente é representante de seu tempo, bem como selecionou em suas memórias as imagens que, ao meu entendimento, são respostas que carregam consigo interpretações suas, a partir de suas ações vividas, que, de certo modo, o leitor possa encontrar concordância em sua experiência de vida.

Por parte destes acadêmicos (a), que estando no Curso de Graduação, selecionaram imagens que também são frutos dos desejos de serem professores, de atuarem semelhantes ou diferentes dos professores que tiveram. Por isso, o cuidado em acreditar que tais professores eram exatamente do modo como foram representados, ou seja, as imagens referem-se aos pontos de vista e conhecimentos dos acadêmicos (a), dos significados que eles adquiriram/formaram da disciplina de História.

Das imagens do (a) professor (a) de História, é pertinente salientar que muitas referências para as representações encontram-se nos posicionamentos teóricos destes professores, seja pela Educação ou pela disciplina de História, uma vez que tais orientações ideológicas marcam profundamente a atuação do docente na sala de aula, como também a compreensão que o docente faz da sua disciplina, da construção de seus conceitos, do uso e da abordagem que se veste este professor (a).

Assim, temos figuras do professor (a) de História como um profissional "chato que fazia a gente decorar datas e acontecimentos sem entender o que aconteceu e porque aconteceu.”. Nas demais disciplinas escolares, não raro, também se percebe o mesmo distanciamento do conteúdo em relação ao seu entendimento.

Deste relato, podemos visualizar um posicionamento da pedagogia tradicional, sendo que, pela História, tal professor (a) seguia uma corrente positivista, priorizando o tempo linear e os fatos memoráveis, como ainda pode se ater alguém que não recebeu uma formação capaz de refletir como se dá a construção dos sabres no campo em que atua: "Existem professores de história que sabem muito, lêem muito e quando chegam diante da turma colocam-se a falar e não param mais, o que torna as aulas 'pobres', sem o envolvimento dos alunos.".

Quanto às imagens que representam 'o (a) professor (a)', houve destaque para o "conservador", "tradicional", sendo que, ao descreverem 'cinco' características que demonstrem 'o que é um (a) professor (a)', surgiram: "crítico, criativo, curioso, descobridor, aquele que reflete".

Estas imagens, no meu entendimento, podem ser alcançadas e até mesmo povoar o imaginário futuro dos discentes e docentes. Para tanto, 
considero que, em seus trajetos de formação, sejam eles na educação básica e, posteriormente, na graduação, como ainda nas pós-graduações, trabalhem-se essas imagens e seus significados, aliados aos elementos constituintes do processo educativo e das disciplinas em suas especificidades.

Acredito assim na necessidade de haver comprometimento e responsabilidade pelo (a) professor (a) com a sua disciplina e com a Educação, em que este imaginário poderá radicalizar-se em favor das trocas de experiências vividas, colocando frente a frente o anseio do "conservador" também se tornar "crítico". Para lembrarmos de professores como "aquele que reflete' é preciso superar a reprodução de instrumentos didáticos sem pensar no real significado que carregam e dão continuidade.

\section{Avaliação: Alternativas Didáticas - Metodológicas}

O trabalho docente é um esforço meticuloso, densamente pensado, discutido e refletido, que se estabelece em consonância com nossas experiências didáticas e delas confrontadas com outras experiências docentes. Assim creio que, para construir novas alternativas didáticas metodológicas, se faz necessário debruçar-se sobre dois aspectos: o planejamento e a avaliação.

Com efeito, o planejamento de ensino e a avaliação são atividades que supõem o conhecimento da dinâmica interna do processo de ensino e aprendizagem e das condições externas que co-determinam a sua efetivação. O planejamento escolar é uma tarefa docente que inclui tanto a previsão das atividades didáticas em termos da sua organização e coordenação em face dos objetivos propostos, quanto a sua revisão e adequação no decorrer do processo de ensino. O planejamento é um meio para se programar as ações docentes, mas é também um momento de pesquisa e reflexão intimamente ligado à avaliação. (LIBÂNEO, 1994, p. 221)

Considerando-se as especificidades da disciplina de História, temse, como conhecimento de suas práticas e intervenções pedagógicas, aulas que, por longo tempo, priorizaram a exposição oral do conteúdo por parte do professor e a passividade dos alunos, por vezes escutando, outras lendo e copiando a matéria transmitida. As formas utilizadas para avaliar a aprendizagem dos alunos resumiam-se, em sua maioria, à resolução de provas escritas ou mesmo orais, em que os alunos respondiam conforme o texto 


\section{L. Squarcieri de Oliveira}

lido ou assimilado mediante a leitura do professor, ignorando os conhecimentos advindos dos discentes, das reais experiências deles, do seu cotidiano e, em especial, depositando inteira responsabilidade dos 'fracassos' na falta de esforço dos alunos.

Não recentemente, mas ainda em fase de amadurecimento, começase a apresentar práticas que se opõem a esta didática, onde o professor deixa de ser o centro único do saber no espaço-tempo denominado 'aula' para, então, o aluno adentrar na História como sujeito de seu fazer e de seu aprender. Essa nova visão de educação e da disciplina de História são reflexos de novas concepções a respeito dos aspectos que se relacionam ao processo educacional, como a seleção, a organização e o desenvolvimento do conteúdo a ser trabalhado. Para Freire (1987, p.83-4), o diálogo necessário entre educador - educandos, como proposta de relação horizontal de educação, ganha maior significação quando dedicamos nossa atenção no que pode ter importância e necessidade de ser estudado, ao invés, do que tem obrigatoriamente de ser estudado.

\footnotetext{
O diálogo começa na busca do conteúdo programático. Daí que, para esta concepção como prática da liberdade, a sua dialogicidade comece, não quando o educador - educando se encontra com os educandos - educadores em uma situação pedagógica, mas antes, quando aquele se pergunta em torno do que vai dialogar com estes. [...] Para o 'educador - bancário', na sua antidialogicidade, a pergunta, obviamente, não é a propósito do conteúdo do diálogo, que para ele não existe, mas a respeito do programa sobre o qual ele dissertará a seus alunos. E a esta pergunta responderá ele mesmo, organizando o seu programa. [...] Para o educador - educando, dialógico, problematizador, o conteúdo programático da educação não é uma doação ou uma imposição - um conjunto de informes a ser depositado nos educandos - , mas a devolução organizada, sistematizada e acrescentada ao povo daqueles elementos que este lhe entregou de forma desestruturada.
}

Assim, acredito também nas concepções de avaliação que não priorizam a mensuração de acertos ou erros, perante respostas pré-programadas. Ao contrário disso, aposto em uma avaliação da aprendizagem, em que o aluno possa demonstrar, por diferentes formas de expressão, suas relações de vida com os conteúdos, os quais planejamos para seu ensino. Portanto, além de definirmos uma nova concepção de avaliação, também considero eficaz a adoção da interdisciplinaridade entre História e outras disciplinas do currículo escolar, para que se possa propor ativida- 
des diferenciadas ao trabalhar os distintos conteúdos.

\begin{abstract}
A avaliação é uma tarefa complexa que não se resume à realização de provas e atribuição de notas. A mensuração apenas proporciona dados que devem ser submetidos a uma apreciação qualitativa. A avaliação, assim, cumpre funções pedagógico-didáticas, de diagnóstico e de controle em relação às quais se recorre a instrumentos de verificação do rendimento escolar. (LIBANEO, 1994, p. 195)
\end{abstract}

Ao postular esta concepção, foco a avaliação não exclusivamente no aluno ou no professor, como tão pouco apenas no conteúdo de ensino. A sugestão é que a avaliação da aprendizagem consiga ser um agregador de etapas, oferecendo um diagnóstico tanto ao aluno, sobre seus níveis de aprendizagem, como ao professor, quanto ao seu planejamento.

A avaliação é a reflexão transformada em ação. Ação, essa, que nos impulsiona a novas reflexões. Reflexão permanente do educador sobre sua realidade, e acompanhamento de todos os passos do educando na sua trajetória de construção do conhecimento. [...] Nessa dimensão, avaliar é dinamizar oportunidades de autoreflexão, num acompanhamento permanente do professor que incitará o aluno a novas questões a partir de respostas formuladas. [...] A avaliação deixa de ser um momento terminal do processo educativo (como hoje é concebida) para se transformar na busca incessante de compreensão das dificuldades do educando e na dinamização de novas oportunidades de conhecimento. (HOFFMANN, 2005, p. 17; 19)

Dessa forma, trago para o artigo três atividades desenvolvidas pela/ na disciplina de História, onde se consegue trabalhar diferentes aspectos das aprendizagens dos alunos, tendo como princípio norteador o diálogo constante e a construção conjunta dos conhecimentos entre educador e educandos. As definições/nomes das atividades didáticas e de suas metodologias foram pensadas e empregadas com diferentes conteúdos, sendo que menciono aquelas que considero vitais para outros encaminhamentos. Outras dinâmicas encontram-se publicadas sob a forma de um Caderno Didático organizado para este fim. Cabe também salientar que algumas são variações de jogos ou brincadeiras, mas que adquirem maior tonacidade pela disciplina em questão. Dentre elas, destaco o 'telefone sem fio', 'xerife e ladrão' e uma dinâmica de grupo denominada 'colcha de retalhos'. 


\section{L. Squarcieri de Oliveira}

A atividade do telefone sem fio consiste em demonstrar-se que as ideias perpassadas de pessoas a pessoas ou de grupos para grupos sofrem interferências em seus significados originais, modificando assim a informação e mesmo a interpretação de determinado evento. Considerando que algumas ideias são elaboradas para este fim, ou seja, para que modifiquem seus significados ao longo dos tempos. A atividade se assume como tal ao interagir com alunos que precisam retransmitir determinada frase (exemplo: "Enquanto o dominado não dominar o que o dominador domina, não conseguirá sair de seu estado de dominação.” (SAVIANI. In: FARIA, 1984, p.79), falando ao ouvido do colega. Após uma sequência de pessoas, a frase é dita em voz alta para o restante da turma, ao atingir a última pessoa do círculo, podendo ser pronunciada como a original, ou ainda, como em geral se constata, apresentar divergência da frase inicial. Essa variação em seu sentido e em sua própria organização serve de demonstrativo das diferentes formas de se contar um evento histórico, como também elimina visões autoritárias e positivistas de 'verdades absolutas'.

A interação entre os alunos que, em um primeiro olhar, parece-lhes que estão exercendo uma brincadeira entre si, serve de metáfora para explicar a variação de sentidos que os conteúdos históricos adquirem, quando cada qual apresenta seus argumentos em defesa da modificação da frase. Outros elementos podem ser inseridos, como o uso dos recursos de fontes documentais, que podem ser de diferentes tipos como áudios, imagens ou objetos, que facilitam a memorização e/ou a interpretação do evento em questão.

Outra atividade consiste em um jogo de expressão facial, denominado xerife e ladrão, em que o "ladrão" deve burlar a percepção dos demais participantes (reféns e Xerife) na tentativa de eliminar (piscando o olho) os reféns e não ser desvendado pelo "Xerife".

Ao ser analisado pela ótica do panoptismo, proposto pelos estudos de Foucault (VEIGA-NETTO, 2007), nos sugere que o professor, simbolizando a estrutura arquitetônica da torre central, precisa estar atento aos alunos e às possíveis situações surpresas da sala de aula, além dos 'rótulos' criados pelo sistema; tendo, pelo lado dos alunos, a possibilidade de criar formas de escapar a esta observação e a constante "vigia" imposta pelo professor, ou seja, ao "disciplinamento que cria corpos dóceis". Ainda, como salienta Veiga-Netto (2007, p.66):

Nas palavras de Foucault: 'Daí o efeito mais importante do panóptico: induzir no detento um estado consci 
Avaliação no ensino de História: significados e possibilidades

ente e permanente de visibilidade que assegura o funcionamento automático do poder. Fazer com que a vigilância seja permanente em seus efeitos, mesma que seja descontínua em sua ação'.

Nessa troca de papéis, o 'xerife-professor' encarrega-se desta autoridade para vigiar o grupo, que age a partir desta repressão ou manipulação do 'ladrão-aluno', em que a estrutura panóptica também vai submetendo outros agentes em sua ação, sendo que este 'professor' pode apresentar-se também provável 'ladrão' na medida em que rompe com as estruturas de poder e, como anteriormente o fazia, passa a ser vigiado.

Ao longo da História, muitos autores definem teorias interpretativas que figuram pelo uso da força, como guerras, revoltas, revoluções, massacres; sempre pelo uso contínuo da força e, na sua maioria, contra grupos que não tinham os mesmos meios de defesa. Demonstrar aos alunos que o uso e o domínio da força direcionam para determinadas compreensões do processo histórico é fundamental para entender as peculiaridades do ensino da disciplina.

Por último, destaco também a dinâmica colcha de retalhos:

Também sob este olhar a Colcha pode ser considerada: espaço habitado por diferentes pessoas, cada qual com sua maneira única de ver o mundo, entrecruzando estes diferentes caminhos a colcha é tecida, a partir de aceitações e negações, valores que se unem e se dissociam, vidas que se cruzam, olhares que vão para além da ótica que a escola oferece. E, para não perder a ternura, a inesquecível frase do Caetano: "cada um sabe a dor e a delícia de ser o que é'. (OLIVEIRA; SANTOS, 2008, Revista Virtual Partes).

Partindo do princípio da cooperação, desenvolvem-se estilos variados de expressão, em tecidos, com materiais diversos, com a intenção de compor um mosaico de ideias e compreensões sobre temas característicos da disciplina. Intensificam-se os diálogos com a possibilidade de utilizá-la como painel, expondo em locais de intensa circulação de pessoas.

Acredito especialmente nesta proposta, por apresentar-se metodologicamente flexível, não se compondo de regras preestabelecidas e nem mesmo limitando-se a espaços específicos de educação. Diferentes conteúdos podem ser abordados ao mesmo tempo em que podemos diagnosticar as aprendizagens de nossos alunos.

A interação entre os alunos e o professor, primeiramente, se dá através de um problema colocado no centro das atenções, distribuindo-se dife- 


\section{L. Squarcieri de Oliveira}

rentes recursos para que sirvam de argumentos. Pode ser uma questão como o tráfico negreiro e as políticas de cotas que temos, hoje, nas Universidades. Esta relação entre temas do passado em relação ao nosso tempo presente facilita a compreensão abstrata do tempo, por parte do aluno, que argumenta na condição de sujeito da História, portador de sua opinião que confronta ou concorda com a do colega. Ao invés de pedir um texto ou outra forma de registro, a arte sobre o tecido aguça a vontade de criar algo novo, diferente, em que as conversas entre os participantes é o elemento principal.

\section{Conclusões}

Ao finalizar este artigo, como nos demais que tenho procedido, uma certeza tem me tocado: cada uma dessas elaborações que começa com uma questão inicial, um problema, ao encaminhar para sua conclusão, muitas outras questões aparecem em seu desenvolvimento. São pontos de vistas que vão sofrendo alterações, modificando-se tanto com as leituras como com as análises realizadas.

As análises empreendidas dizem respeito às representações que acadêmicos da Pedagogia - Licenciatura Plena adquiriram de seus professores (a) de História ao longo de seus anos escolares, o que, no meu modo de compreender, se perpetuam na forma como os futuros docentes poderão trabalhar esta disciplina em suas aulas. A questão se intensifica quando proponho semelhante estudo aos professores (a) de História especificamente, e não raro, encontro respostas com significados semelhantes.

Temas ligados a Educação nem sempre são frequentemente trabalhados ou aprofundados conforme a necessidade que demonstram. Trabalhar tendo como base a nossa realidade, ou seja, as nossas experiências como discentes e, posteriormente, como docentes, faz com que contrastamos diferentes opiniões sobre um mesmo tema, percebendo que muito dos significados sociais perpassam por anos sem sofrerem alterações.

Isso pode ser evidenciado por considerar como algo normal, natural, que tem unicamente um sentido, um significado, ou por interesses que ultrapassam a simples aplicação de uma prova por parte do professor (a). Trabalhamos com vários mitos da avaliação da aprendizagem que povoam nosso imaginário, sendo importante questionar nossas imagens, para então apresentarmos coerência entre nossos discursos e nossas ações. 


\section{Referências}

ARÓSTEGUI, Julio. A pesquisa Histórica: teoria e método. Tradução: Andréa Dore; revisão José Jobson de Andrade Arruda. Bauru, SP: EDUSC, 2006.

ARRUDA, Ângela (org.). Representando a Alteridade. Rio de Janeiro: Petrópolis, Editora Vozes, 1998

FARIA, Ana Lúcia G. de. Ideologia no livro didático. São Paulo: Cortez/Autores Associados, 1984.

FREIRE, Paulo. Pedagogia do Oprimido. Rio de Janeiro, JR: Editora Paz e Terra, $17^{\text {a }}$ Edição, 1987.

HOFFMANN, Jussara. Avaliação Mediadora: uma prática em construção da pré-escola à universidade: Porto Alegre, RS: Editora Mediação, $23^{\mathrm{a}}$ ed., 2003.

\section{Avaliação - mito e desafio: Uma Perspectiva}

Construtivista. Porto Alegre, RS: Editora Mediação, 35 a Edição, 2005.

JOSSO, Marie-Christine. Experiências de vida e formação. Trad.: José Claudino e Júlia Ferreira. São Paulo: Cortez, 2004.

KARNAL, Leandro (org.). História da Sala de Aula: conceitos, práticas e propostas. 3 ed. São Paulo: Contexto, 2005.

LIBÂNEO, José Carlos. Didática: Coleção Magistério - $2^{\circ}$ Grau - Série Formação do Professor. São Paulo: Cortez, 1994.

LÜDKE, Menga; ANDRÉ, Marli. Pesquisa em Educação: Abordagens Qualitativas. São Paulo: EPU, 1986.

SANTOS, F. G. S., OLIVEIRA, D. L. S. Costurando Saberes Através da Colcha de Retalhos: Aprendendo a Dialogar com Diferentes Áreas do Saber. Revista Virtual Partes - Educação., out. 2008, p.1 - 3. Disponível na Web: http://www.partes.com.br/educacao/ costurandosaberes.asp. ISSN: 1678-8419.

VASCONCELLOS, Celso dos S. Avaliação: concepção dialéticalibertadora. São Paulo, SP: Libertad, 13ª ed., 2001.

VEIGA-NETO, Alfredo. Foucault \& a Educação. $2^{\mathrm{a}}$ ed. Minas Gerais: Belo Horizonte, Autêntica, 2007. 
Décio Luciano Squarcieri de Oliveira

Mestrando em Educação na Universidade Federal de Santa Maria, Professor Pesquisador I da UAB/UFSM, Pedagogia Licenciatura Plena - EAD.

E-mail para correspondência:

decioluciano@yahoo.com.br 